\title{
Atypical Epidermoid Cyst in Renal Pelvis and Histogenetic Implications
}

\author{
Jai Hyang Go, Jeong Hee Hong ${ }^{1}$, Gilho Lee ${ }^{1}$ \\ Departments of Pathology and ${ }^{1}$ Urology, Dankook University College of Medicine, Cheonan, Korea
}

\begin{abstract}
Since the renal epidermoid cyst is too rare, the mechanisms of squamous morphogenesis have not well characterized. A 73-yearold female was referred with an incidentally detected renal pelvis mass. Abdominopelvic computed tomography scan revealed a noncalcified soft tissue mass in the renal pelvis. Total nephroureterectomy was performed under the impression of a renal pelvis malignancy. The patient was discharged without postoperative complication. The outer surface of mass lesion was lined with urothelia and squamous epithelia, containing keratinous materials. The urothelia were positively stained against uroplakin II and cytokeratin 7, whereas almost of the squamous epithelia were negative with uroplakin II. The two different epithelia were generally sharply demarcated. Interestingly, some part of squamous epithelia contained uroplakin-positive and many more cytokeratin 7-positive cells. The atypical clinical features in our case can reconsider the diagnostic clues of renal epidermoid cysts that have been reported before, and the unique immunohistochemical results may understand the histogenetic implications of the lesion.
\end{abstract}

Keywords: Epidermal cyst; Uroplakins; Pathology; Kidney

Epidermoid cyst in the kidney occurs very rarely and only a few cases have been reported in the literature [1-6]. Although it is a very uncommon lesion, a calcified intrarenal lesion has to be suggested as an important landmark for differential diagnosis of renal epidermoid cyst [3]. Because the epidermoid cyst is benign, renal preservation surgery can be an appropriate management if a prompt diagnosis is preoperatively made [6]. However, a noncalcified soft tissue mass in the renal pelvis is highly suggestive of urothelial carcinoma, nephroureterectomy should be basically considered. It has been discussed that the epidermal remnant of Wolffian duct, squamous metaplasia after chronic irritation with urinary stone $[2,3,6]$, and traumatic implantation [2,6] are possible cause of a renal epidermoid cyst. The transitional epithelium, known as urothelium, is a distinctive structure covering in the urinary tract. Uroplakins consists of apical urothelial membrane and are considered to be a biochemical marker of urothelial differentiation [7]. Is there any cellular basis of urothelial squamous metaplasia in the development of epidermoid cyst in the renal pelvis? It is not clear what the role of uroplakins in the squamous metaplastic lesion. Herein, we report an atypical case of an epidermoid cyst in the renal pelvis with an emphasis on its histogenetic origin using immunohistochemistry.

\section{CASE REPORT}

A 73-year-old female was admitted for surgical removal of a left renal pelvic mass. She has taken antihypertensive agents for 30 years and received percutaneous coronary intervention due to stable angina 3 years ago. During routine follow-up, a renal mass was incidentally detected 2 months ago. She denied any episodes of renal colic or urolithiasis. On physical examination, there was no tenderness on the area of costovertebral angle. Laboratory values revealed a marginal elevation of serum creatinine
Corresponding author: Gilho Lee

Department of Urology, Dankook University College of Medicine,

119 Dandae-ro, Dongnam-gu, Cheonan 330-997, Korea

Tel: +82-41-550-3963 / Fax: +82-41-551-6630 / E-mail: multiorigins@yahoo.com

Submitted: July 31, 2012 / Accepted after revision: December 24, 2012
This is an Open Access article distributed under the terms of the Creative Commons Attribution Non-Commercial License (http://creativecommons.org/licenses/by-nc/3.0/) which permits unrestricted non-commercial use, distribution, and reproduction in any medium, provided the original work is properly cited. 
$(1.21 \mathrm{mg} / \mathrm{dL})$. Urinalysis and urine cytology showed no evidence of inflammation or malignant cells. The ultrasonography showed an echogenic mass within the renal pelvis and mild dilation of several calyces. The calcified lesion was not found on plain radiograph of the abdomen (kidneys, ureters, and bladder). An abdominopelvic computed tomography revealed a noncalcified soft tissue mass in the left renal pelvis on precontrast enhancement scan. It showed slight enhancement after contrast administration (Fig. 1A). The preoperative radiologic diagnosis was favored as a urothelial carcinoma of the renal pelvis. A conventional left nephroureterectomy was performed.

The cut surface of the resected specimen revealed a $5 \times 3 \times 2$ $\mathrm{cm}$-sized, well-defined ovoid, cystic mass which was compactly filled with white and reddish tan-colored amorphous materials in the pelvis. Histologically, the cystic lumen contained multiple keratinous materials and much of the cystic lining epithelia were denuded. The remaining portion was lined with hyperplastic urothelium and keratinizing squamous epithelium (Fig. 1B). These two epithelial areas were sharply demarcated from each other. Immunohistochemical staining using antibodies against uroplakin II (1:100; Santa Cruz Biotechnology Inc., Santa Cruz, CA, USA) and cytokeratin 7 (CK7) (1:100; Dako, Glostrup, Denmark) was performed to identify epithelium-specificdifferentiation. The cells lining urothelia were strikingly positive for uroplakin II (Fig. 1C) and CK7. In contrast, most of the cells in the lining of squamous epithelia were negative for these urothelial
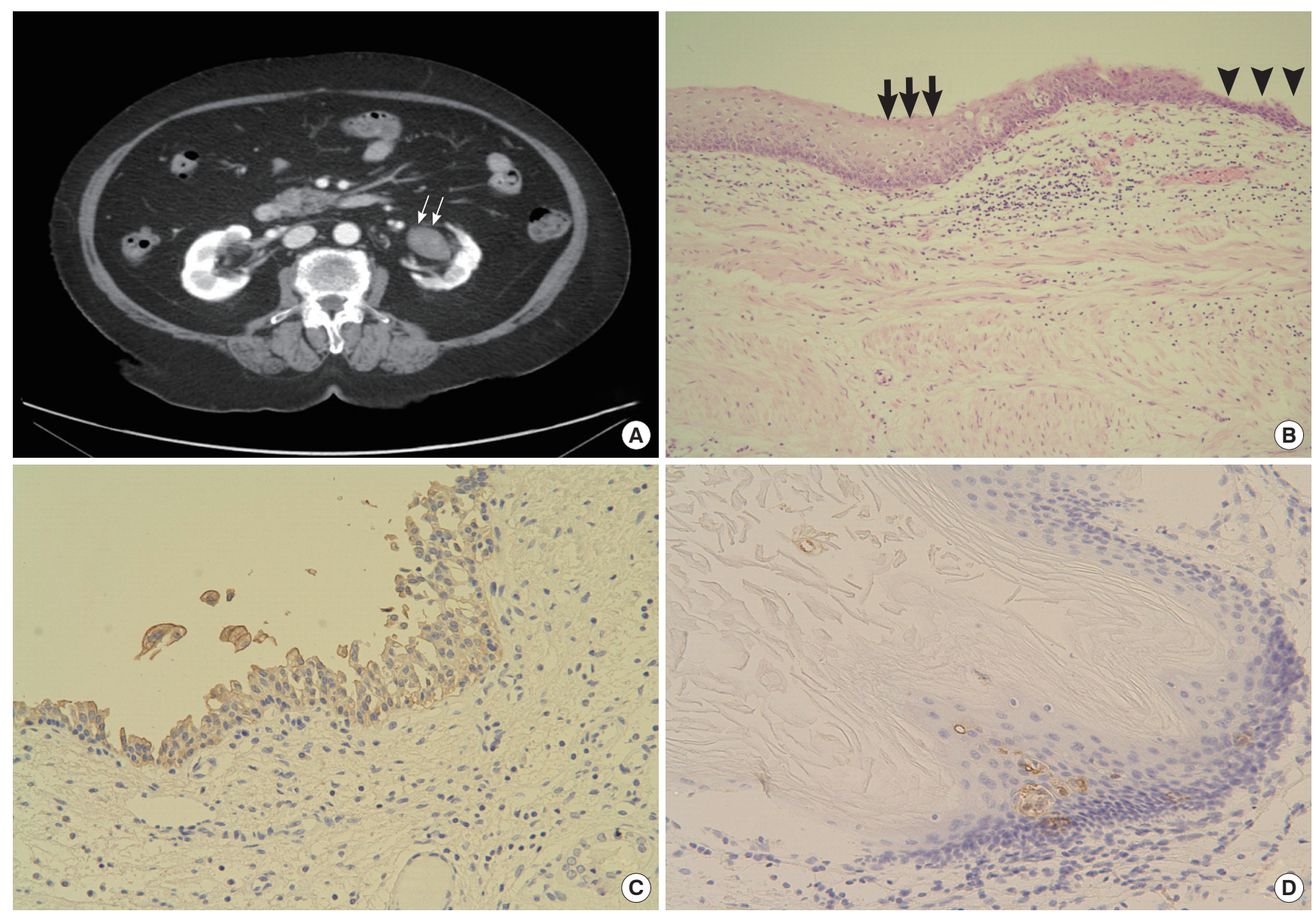

Fig. 1. (A) Abdominopelvic computed tomography shows a noncalcified soft tissue density, measuring $2.7 \times 1.7 \mathrm{~cm}$, in the left renal pelvis with weak enhancement on postcontrast enhancement scan (arrows). The enhanced Hounsfield units (HU) of mass was $25 \mathrm{HU}$ compared with the findings on unenhanced images. (B-D) Microscopic findings; (B) An epidermoid cyst is lined by urothelium (arrowheads) and keratinizing squamous epithelium (arrows) (H\&E, $\times 100)$. (C) The majority of the cells of the cyst lining urothelia are positive for uroplakin II (antiuroplakin II antibody, $\times 100$ ). (D) Some portions of the squamous epithelia in the cyst contain a few uroplakin-positive cells (antiuroplakin II antibody, $\times 100$ ). 
Table 1. Characteristics of reported cases with intrarenal epidermoid cyst

\begin{tabular}{|c|c|c|c|c|c|c|c|c|}
\hline Author & Sex & $\begin{array}{l}\text { Age } \\
(\mathrm{yr})\end{array}$ & Symptoms & $\begin{array}{l}\text { Radiologic } \\
\text { presentation }\end{array}$ & $\begin{array}{l}\text { Presence of } \\
\text { calcification }\end{array}$ & $\begin{array}{l}\text { Association } \\
\text { with stones }\end{array}$ & Preoperative impression & Surgical treatment \\
\hline Emtage and Allen [1] & $\mathrm{F}$ & 74 & Flank pain & Renal mass & Unknown & Unknown & Renal cell carcinoma & Radical nephrectomy \\
\hline Lim and Kim [2] & $\mathrm{M}$ & 51 & Flank pain & Renal mass & Yes & Renal stone & Cystic renal mass & Simple nephrectomy \\
\hline Gokce et al. [3] & $\mathrm{F}$ & 55 & Flank pain & Renal pelvis mass & Yes & Renal stone & Renal pelvis tumor & Nephroureterectomy \\
\hline Abdou and Asaad [4] & M & 67 & Flank pain & Renal mass & No & No & End stage renal disease & Simple nephrectomy \\
\hline Dadali et al. [5] & $\mathrm{F}$ & 48 & Flank pain & Atrophic kidney & No & No & Chronic pyelonephritis & Simple nephrectomy \\
\hline Bauer et al. [6] & $\mathrm{F}$ & 68 & Flank pain & Renal pelvis mass & Yes & Renal stone & $\begin{array}{l}\text { Epidermal cyst through } \\
\text { ureterorenoscopic biopsy }\end{array}$ & Partial nephrectomy \\
\hline Present case & $\mathrm{F}$ & 73 & Absent & Renal pelvis mass & No & No & Renal pelvis tumor & Nephroureterectomy \\
\hline
\end{tabular}

specific antibodies. However, some portion of the squamous epithelia interestingly contained a few uroplakin-positive cells (Fig. 1D) and some more CK7-positive cells.

\section{DISCUSSION}

Even though the epidermoid cyst of the kidney is a very rare to be characterized, the typical features of the lesion can be summarized as follows. The clinical symptoms are flank pain, gross hematuria, or lower urinary tract symptoms. The epidermoid cysts are usually found as an intrarenal lesion $[1,2,4,5]$. The calcified inhomogeneous lesion, combined renal stone, and previous renal surgery are other important clinical clues for the renal epidermoid cyst (Table 1). To date, two cases of epidermoid cyst in the renal pelvis have been reported. They also showed a typical calcified lesion combined with renal stone like other renal epidermoid cysts $[3,6]$. With these reasons, it seemed hard to think of epidermoid cyst as a presumptive diagnosis before surgery in this case. To the best of our knowledge, this case of a noncalcified epidermoid cyst in the renal pelvis is the first report in the English literature.

The histology of a typical epidermal cyst that was lined by stratified squamous cells with laminated keratins. Although epidermoid cyst of the skin is a common lesion resulted from implantation of epidermis into the dermis, histogenesis of epidermoid cyst in the kidney remains uncertain. As a possible histogenetic mechanism, either epidermal embryonic remnants of Wolffian ducts or traumatic implantation of transformed epithelial cells during renal operation have been proposed. The extension of squamous metaplastic changes from the upper ureter to the pelvocalyceal system in prolonged irritative condition induced mostly by stones is considered as the other plausible ex- planation $[2,3,6]$. However, the cellular basis of squamous metaplasia is not fully understood in this rare condition.

The urothelium forms an extraordinarily effective permeability barrier. To perform these functions, the apical surface of urothelium is highly specialized as it is covered almost by urothelial plaques which are composed of uroplakins [7]. Four uroplakins (Ia, Ib, II, and III) have been isolated and are considered to be biochemical markers of terminal urothelial differentiation. CK7 is an intermediate filament proteins expressed in a wide variety of simple epithelia but not in the squamous epithelia. Normal urothelium and urothelial tumors express CK7 in a significant percentage of cases [8]. Therefore, CK 7 is also considered to be a marker of urothelial differentiation.

It is well known that vitamin A deficiency can induce keratinizing squamous metaplasia in a variety of epithelia including urothelium[9]. Recently, the heterogeneity in urothelial metaplasia has been reported [7]. The urothelial keratinization in the vitamin A-deficient mice bladder occurred heterogeneously adjacent to areas lined with normal appearing urothelium. The sharp boundary between the keratinized epithelium and the seemingly normal urothelium was maintained with no intermediated cells. According to the our histologic examination, nearly almost of the urothelial cells in the cystic lining were positively stained against both uroplakin II and CK7, but most of the squamous epithelial cells were negative for these antibodies. The two epithelia were sharply delineated and more distinctly distinguishable in the immunohistochemical stained sections. These features were similar with heterogenous metaplasia of the animal urothelium in the previous study [7]. However, some squamous epithelia contained a few uroplakin-positive cells and CK7-positive cells to some extent. Even though the significance of few uroplakin expressions in squmous epithelium should be 
evaluated by other studies, is this an indirect evidence of the direct transformation of umbrella cells to squamous metaplasia or dedifferenctiation of metaplastic squamous epithelium to urothelium?

\section{CONFLICT OF INTEREST}

No potential conflict of interest relevant to this article was reported.

\section{REFERENCES}

1. Emtage LA, Allen C. A renal epidermoid cyst. Br J Urol 1994;74: 125-6.

2. Lim SC, Kim CS. Intrarenal epidermal cyst. Pathol Int 2003;53:574-8.

3. Gokce G, Kaya K, Kilicarslan H, Tas F, Ayan S, Yildiz E, et al. Epidermoid cyst in the renal pelvis. Int Urol Nephrol 2003;35:9-10.

4. Abdou AG, Asaad NY. Intrarenal epidermoid cyst presented as an enlarged multicystic kidney. Saudi J Kidney Dis Transpl 2010;21: 728-31.

5. Dadali M, Emir L, Sunay M, Ozer E, Erol D. Intrarenal epidermal cyst. Kaohsiung J Med Sci 2010;26:555-7.

6. Bauer RM, Siegert S, Nordhaus C, Staehler M. Epidermoid cyst of the kidney: a rare cause of recurrent renal colic. Urologe A 2010; 49:540-2.

7. Liang FX, Bosland MC, Huang H, Romih R, Baptiste S, Deng FM, et al. Cellular basis of urothelial squamous metaplasia: roles of lineage heterogeneity and cell replacement. J Cell Biol 2005;171:83544.

8. Logani S, Oliva E, Amin MB, Folpe AL, Cohen C, Young RH. Immunoprofile of ovarian tumors with putative transitional cell (urothelial) differentiation using novel urothelial markers: histogenetic and diagnostic implications. Am J Surg Pathol 2003;27:1434-41.

9. Molloy CJ, Laskin JD. Effect of retinoid deficiency on keratin expression in mouse bladder. Exp Mol Pathol 1988;49:128-40. 